25. Kawakubo, A., Makino, H., Ohnishi, J. I., Hirohara, H. and Hori, K., The marine red alga Eucheuma serra J. Agardh, a high yielding source of two isolectins. J. Appl. Phycol., 1997, 9, 331338 .

26. Gilboa-Garber, N., Citronbaum, R., Levence, C. and Sela, R., H blood group detection by the L-fucose binding lectin of the green marine alga Ulva lactuca. Dev. Comp. Immunol., 1988, 12, 695705.

27. Chiles, T. C. and Bird, K. T., A comparative study of animal erythrocyte agglutinins from marine algae. Comp. Biochem. Physiol., 1989, 94(1), 107-111.

28. Sampaio, A. H., Rogers, D. J. and Barwell, C. J., Characterization of a new lectin from the green marine alga Ulva laetevirens. In Lectins: Biology, Biochemistry, Clinical Biochemistry (eds Kilpatrick, D. C., Van Driessche, E. and Bg-Hansen, T. C.), Textop Hellerup, Denmark, 1996, vol. 11, pp. 96-100.

29. Sampaio, A. H., Rogers, D. J. and Barwell, C. J., Isolation and characterization of the lectin from the green marine alga Ulva lactuca L. Bot. Mar., 1998, 41, 427-433.

30. Li, D. T., Cui, T. J., Lu, Q., Xu, Z. Y., Gao, Q. L. and Xu, Q. L., Isolation, purification and properties of lectin from Ulva pertusa. Chin. J. Biochem. Mol. Biol., 2000, 16(6), 774-778.

31. Shiomi, K., Yamanaka, H. and Kikuchi, T., Purification and physicochemical properties of a hemagglutinin (GVA-1) in red alga Gracilaria verrucosa. Bull. Jpn. Soc. Sci. Fish., 1981, 47(8), 1079-1084.

32. Hori, K., Miyazawa, K. and Ito, K., Some common properties of lectins from marine algae. Hydrobiologia, 1990, 204-205, 561566.

33. Nagano, C. S. et al., Purification and characterization of a new lectin from the red marine alga Hypnea musciformis. Protein Peptide Lett., 2002, 9(2), 159-165.

34. Fábregas, J., Llovo, J. and Muñoz, A., Hemagglutinins in red seaweeds. Bot. Mar., 1985, 28, 517-520.

ACKNOWLEDGEMENTS. This work was supported by a research grant (DBT-JRF program in Biotechnology and Applied Biology) from Department of Biotechnology (DBT), New Delhi (India). The author Mr S. Kumar was a recipient of a Senior Research Fellowship from DBT, GoI. We acknowledge the Blood Bank, Goa Medical College, for supply of blood. We wish to thank Dr Vijaya Kerkar, Goa University for identifying the algae, Dr M. S. Shailaja for fine-combing this manuscript, Perantho Dias (SRF) for his help in preparation of the manuscript and last but not the least the maker of nature who has endowed us with myriad organisms and avenues to study and marvel at!

Received 29 June 2018; revised accepted 22 October 2019

doi: $10.18520 / \mathrm{cs} / \mathrm{v} 118 / \mathrm{i} 4 / 621-625$

\section{Marker validation and sequencing in aromatic landrace Mushk Budji}

\author{
Aafreen Sakina and Amjad M. Husaini*
}

Division of Plant Biotechnology, Sher-e-Kashmir University of Agricultural Sciences and Technology of Kashmir, Shalimar, Jammu and Kashmir 190 025, India

Aroma trait imparts specialty to rice and enhances its economic value in the market. Most aromatic genotypes are known to possess a truncated version of betaine aldehyde dehydrogenase gene, imparting aroma. Temperate rice varieties of Kashmir, India, have not been assessed for allelic variants of this fragranceimparting gene. Herein we report allelic variations present in exon 7 of this gene in the popular scented rice Mushk Budji. Unlike basmati-type genotypes, Mushk Budji is a short and bold japonica rice which grows at high altitudes and is cold-tolerant. Moreover, aroma retention after cooking is better in Mushk Budji compared to Pusa Sugandh 3, a long and thin basmati-type rice adapted to low-altitude areas of the Kashmir valley. Analysis showed the presence of a deletion of 8 bps 'GATTATGG' and three single nucleotide polymorphism in exon 7 of aromatic rice genotypes, including Mushk Budji. No such deletion was found in non-aromatic rice varieties. Additionally, one functional marker for badh2 allele was validated in Mushk Budji. These findings can facilitate the development of short and bold fragrant rice varieties through marker assisted selection, especially for highaltitude cold regions and the temperate valley conditions of Kashmir and the rest of India.

Keywords Aromatic landrace, functional markers, sequencing.

GRAIN aroma is the single-most attractive character for rice consumers. There is an increased global demand for aromatic rice varieties because of their pleasant aroma and superior nutritional quality, owing to better amino acid profiles ${ }^{1}$. 2-Acetyl-1-pyrroline [2AP; IUPAC name 5-acetyl-3,4-dihydro-2 $H$-pyrrole] is a major chemical compound responsible for the fragrance of aromatic rice ${ }^{2}$. Aroma characteristics are found within three of the distinguished genetic subpopulations of rice: Group V (Sadri and Basmati), indica (Jasmine) and tropical japonica ${ }^{3}$. Mushk Budji, a temperate japonica variety is the most prominent aromatic indigenous rice cultivar of Kashmir, India $^{4,5}$. However, this cultivar was mostly grown as admixtures of Mushk Budji false dublicates by the farmers and there were complaints from consumers regarding the aroma quality in local markets. Keeping this in view, a massive genetic purification programme was conducted over a period of four years (2008-12) at the

*For correspondence. (e-mail: amjadhusaini@skuastkashmir.ac.in) 
Mountain Research Centre for Field Crops, Khudwani, Jammu and Kashmir, India by Amjad M. Husaini and colleagues at MRCFC. Three accessions were found to possess good-quality aroma and better yield (4.0-4.5 tonne/ ha). These accessions were bulked and the purified landrace was multiplied under participatory mode and released by Sher-e-Kashmir University of Agricultural Sciences and Technology of Kashmir (SKUAST-K) for commercialization under public-private partnership mode in 2014. Mushk Budji not only smells good but also tastes better and therefore fetches good economic returns for the farmers.

The major problem, however, with Mushk Budji is its high susceptibility to rice blast (Magnaporthe grisea), making it risky from the farmers' perspective. A viable alternative could be the introduction of aromatic rice varieties from other regions of India. However, the aromatic varieties which were introduced from subtropical regions of the country either face maturity problems because of cold temperate conditions in Kashmir, or problems related to milling facilities/properties ${ }^{6}$. As such, genetic improvement of Mushk Budji has become imperative for livelihood security of these rice farmers. A major bottleneck, however, is the lack of knowledge about the genetic origin of fragrance in it. Genetic origin of aroma in rice is a matter of interest among rice breeders. While some have deciphered fragrance to be controlled by monogenic inheritance $^{7}$, others contend it to be a quantitative trait ${ }^{8}$. Nevertheless, a significant major gene regulating aroma production in almost all fragrant rice varieties is a single recessive gene located on chromosome 8 , and has been identified by different techniques, viz. RFLP (ref. 9), and SSR markers RM210 and RM515 (ref. 10). This gene encodes an enzyme betaine aldehyde dehydrogenase (BADH2) composed of 503 amino acids ${ }^{11}$. Bradbury et $a l .{ }^{12}$ on sequencing found an eight base-pair deletion and 3 single nucleotide polymorphism (SNPs) in exon 7 of badh2 gene (badh2.1 allele). They hypothesized that it leads to the generation of a premature stop codon, which blocks the function of badh2 and renders it nonfunctional. In addition, different allelic variants that contribute to fragrance have been identified by other workers. For example, a 7-bp deletion in exon 2 (ref. 13), two new SNPs in the central section of intron 8 (ref. 14), absence of MITE (miniature interspersed transposable element) in the promoter ${ }^{15}$, a TT deletion in intron 2 and a repeated (AT)n insert in intron 4 of badh2 (ref. 16) have been implicated for aroma production in different rice varieties.

Marker-assisted breeding is one of the most viable techniques for rice improvement. Kashmir genotypes, especially Mushk Budji, need to be screened for the presence of badh2.1 allele. Different marker systems that target the above-mentioned deletions and provide insight into the type of alleles regulating fragrance have been already developed. Sakthivel et al. ${ }^{17}$ developed a marker
BADEX7-5 for discriminating fragrant from non-fragrant genotypes. It targets the InDel polymorphism in badh2.1 gene and amplifies a 95 and 103 bp fragment in fragrant and non-fragrant genotypes respectively. Since badh2.1 is the abundant allele and has been found in maximum genotypes studied ${ }^{12,13}$, we chose to screen Kashmir genotypes for its presence and sequence the region for assessing allelic variations between them. Further, we chose to validate the efficiency of the functional marker BADEX7-5, so that it could be used in the breeding of these fragrant rice varieties through marker assisted selection (MAS). Herein we report allelic variations present in exon 7 of badh2.1 gene in these rice genotypes, including the famous high-altitude scented rice Mushk Budji.

Five genotypes of rice were chosen for the study. These comprised of japonica-type aromatic landrace 'Mushk Budji', basmati variety introduced in Kashmir 'Pusa Sugandh-3', japonica-type non-aromatic landrace 'Kawa Kreed', indica-type popular rice variety 'Jehlum' and a genotype with disputed identity 'Kamad'. (This genotype was procured from a farmer who claimed it to be Kamad, but our preliminary analysis showed it was nonaromatic. Therefore, we included it in the present study to ascertain its genetic nature. Due to its suspicious identity, it has been referred as Kamad? in the present study; Figure 1.) The phenotypes of all these genotypes were classified as fragrant or non-fragrant by tasting dehulled seeds according to the method of Berner and Hoff ${ }^{18}$. Twelve seeds from each genotype were chewed individually and scoring for grain aroma was done on a 0-5 scale, with 5 as the 'most' aromatic and 0 with 'no' aroma.

For genetic study, the seeds of these five genotypes were sown in clay soil in pots (triplicate) and kept in a glass house maintained at $25^{\circ} \pm 2{ }^{\circ} \mathrm{C}$. Young leaf samples were collected from 18-day-old seedlings for the isolation of genomic DNA. Harvested leaves were placed in glassine bags and stored at $-20^{\circ} \mathrm{C}$.

Plant DNA was isolated from the young harvested leaves using CTAB (cetyl trimethyl ammonium bromide) method, as modified by Saghai-Maroof et al. ${ }^{19}$. Quality and quantity of DNA were determined by UV-visible spectrophotometer (HITACHI U-2800, SKUAST-K). Two primer pairs were used for PCR amplification of the target sequences: (1) BADEX7-5 (F)5'TGTTTTCTGTTTAGGTTGCATT3' (R)5'ATCCACAGAAATTTGGAAAC3' $^{\prime}$ gene-specific marker that targets the InDel polymorphism in exon 7 of badh2 (ref. 17) and (2) OsBADH2 (F) 5'ACATAGTGACTGGATTAGGTTCTG3' (R) 5'CATCAACATCATCAAACACCACT3' for amplification of exon 7 region of badh 2 gene $^{20}$. Amplifications with BADEX7-5 were performed in a $20 \mu \mathrm{l}$ reaction mixture containing $2.0 \mu \mathrm{l}$ PCR buffer, $1.2 \mu \mathrm{l}(25 \mathrm{mM})$ $\mathrm{MgCl}_{2}, 4 \mu \mathrm{l}(1 \mathrm{mM}) \mathrm{dNTPs}, 1 \mu \mathrm{l}(10 \mathrm{mM})$ primer each forward/reverse, $0.25 \mu \mathrm{l}$ Taq DNA polymerase and $1 \mu \mathrm{l}$ (25 ng) template DNA. PCR with $O S B A D H 2$ was carried 

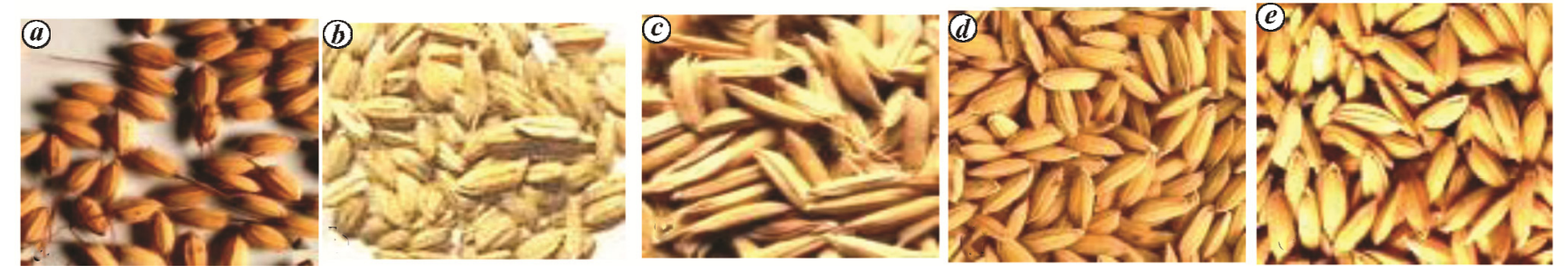

Figure 1. Grain of rice genotypes. $\boldsymbol{a}$, Mushk Budji; $\boldsymbol{b}$, Kawa Kreed; $\boldsymbol{c}$, Pusa Sughandh-3; $\boldsymbol{d}$, Jehlum; $\boldsymbol{e}$, Kamad.

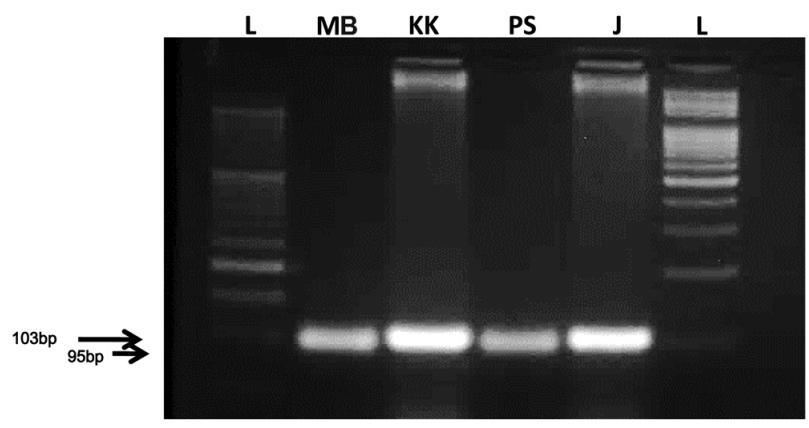

Figure 2. PCR amplification using functional marker BADEX7-5. Lane L, 50 bp ladder; lane MB, Mushk Budji F; lane KK, Kaw Kreed; lane PS, Pusa Sughandh-3; lane J, Jehlum and lane L, 100 bp ladder. Each aromatic genotype amplified a $95 \mathrm{bp}$ fragment while the nonaromatic genotype amplified $103 \mathrm{bp}$ fragment.

out in $50 \mu \mathrm{l}$ reaction mixture containing $5 \mu \mathrm{l}$ PCR buffer, $5 \mu \mathrm{l}(25 \mathrm{mM}) \mathrm{MgCl}_{2}, 10 \mu \mathrm{l}(1 \mathrm{mM}) \mathrm{dNTPs}, 4 \mu \mathrm{l}(10 \mathrm{mM})$ primer each forward/reverse, $0.25 \mu \mathrm{l}$ Taq DNA polymerase, $4 \mu \mathrm{l}(25 \mathrm{ng})$ template DNA and $5 \mu \mathrm{l}$ DMSO. Temperature profile of the thermal cycler was identical for both primers: initial denaturation for $5 \mathrm{~min}$ at $94^{\circ} \mathrm{C}$ followed by 35 cycles of denaturation at $94^{\circ} \mathrm{C}$ for $15 \mathrm{sec}$, $30 \mathrm{sec}$ annealing at $50^{\circ} \mathrm{C}$ for $15 \mathrm{sec}, 30 \mathrm{sec}$ extension at $72^{\circ} \mathrm{C}$ and a final extension of $72^{\circ} \mathrm{C}$ for $30 \mathrm{~min}$. The PCR products were resolved on 3.5\% Electrophoresis Matrix low EEO agarose 1 (G Biosciences, St. Louis, MO, USA) gel stained with $0.5 \mu \mathrm{g} / \mathrm{ml}$ ethidium bromide and visualized in a Gel Documentation System (BioRad, SKUAST-K). The bands corresponding to fragrant and non-fragrant genotypes were scored visually.

The $30 \mu \mathrm{l}$ PCR product $(200 \mathrm{ng} / \mu \mathrm{l})$ of each sample amplified using OsBADH2 primer pair was cut from the gel and sent for sequencing (SciGenomics labs, Cochin). Primers OsBADH2 R/F (60 ng/ $\mu \mathrm{l}) 20 \mu \mathrm{l}$ were sent along with the PCR products. In silico analysis was done using freely available software tools on portal of the National Centre for Biotechnology Information (NCBI), USA (http://www.ncbi.nlm.nih.gov). ClustalW (www.genome. $\mathrm{jp} /$ tools/clustalw) was used for creating multiple sequence alignment in the region of interest. After annotation, the sequences were submitted to NCBI.

Results of Berner and Hoff test showed that Mushk Budji had good aroma with a score of 5. Pusa Sugandh-3 was found to be equally fragrant (score 5). Kamad?,
Kawa Kreed and Jehlum were found to be non-fragrant with a score of 0.

Functional marker BADEX7-5 developed by Sakthivel et $a l .{ }^{17}$ was validated in the genotypes of Kashmir as well as Pusa Sugandh 3. The Basmati varieties tested so far were Basmati 217, Basmati 370, Basmati 386, Type-3, Taroari Basmati, Ranbir Basmati, Kasturi, Super Basmati, Haryana Basmati, Punjab Basmati, Mahi Sugandha, Pusa Basmati-1 and Pusa 1121. The short-grain aromatic varieties tested were Pankhari 203, Seetabhog, Tilakchandan, Tulasi Amrit, Tulsimanjari, Amritsari, Ambemohar, Badshah, Badshah bhog, Badshahbhog joha, Baspatri, Bansphool A, Chini kamini, Dubraj, Dhusara Badshah bhog, Govinda bhog, Jeeraga Samba, Kala namak, Kanak jeer, Katari bhog, Kola joha and Kunikuni joha $^{17}$. In the present study, BADEX7-5 generated a fragment of approximately $96 \mathrm{bp}$ in both fragrant rice varieties. This indicates the presence of the 'fragrant' allele badh2.1 (which possesses a 7 bp deletion and three SNPs in exon 7). On the contrary, BADEX7-5 marker generated a 103-bp PCR product for non-fragrant genotypes Jehlum and Kawa Kreed, predicting the absence of badh2.1 allele in these genotypes (Figure 2). These results confirm that the marker targets this functional InDel polymorphism and can therefore be used for genotyping fragrance trait in these rice genotypes. Hence the validation of this important functional marker for badh2 allele in Mushk Budji and Pusa Sugandh-3 (aromatic varieties) opens the possibility of using it in marker-assisted breeding for the development of fragrant rice varieties for temperate and high-altitude regions of Kashmir valley.

Although molecular marker BADEX7-5 differentiated aromatic and non-aromatic genotypes in the present study by generating products of two different sizes, viz. $96 \mathrm{bp}$ in aromatic and $103 \mathrm{bp}$ in non-aromatic varieties, and visualized by the difference in position of bands obtained after electrophoresing the two products on a $3.5 \%$ agarose gel, in order to confirm that it is the same deletion of $8 \mathrm{bp}$ as observed by Bradbury et al. ${ }^{12}$, the target region was amplified using another set of primers (OsBADH2) and subsequently sequenced using the Sanger method. Mushk Budji represented aromatic japonica group, Pusa Sugandh 3 represented Sadri and Basmati (indica group), Kawa Kreed represented non-aromatic japonica group, and Jehlum represented non-aromatic indica group. Kamad? was 

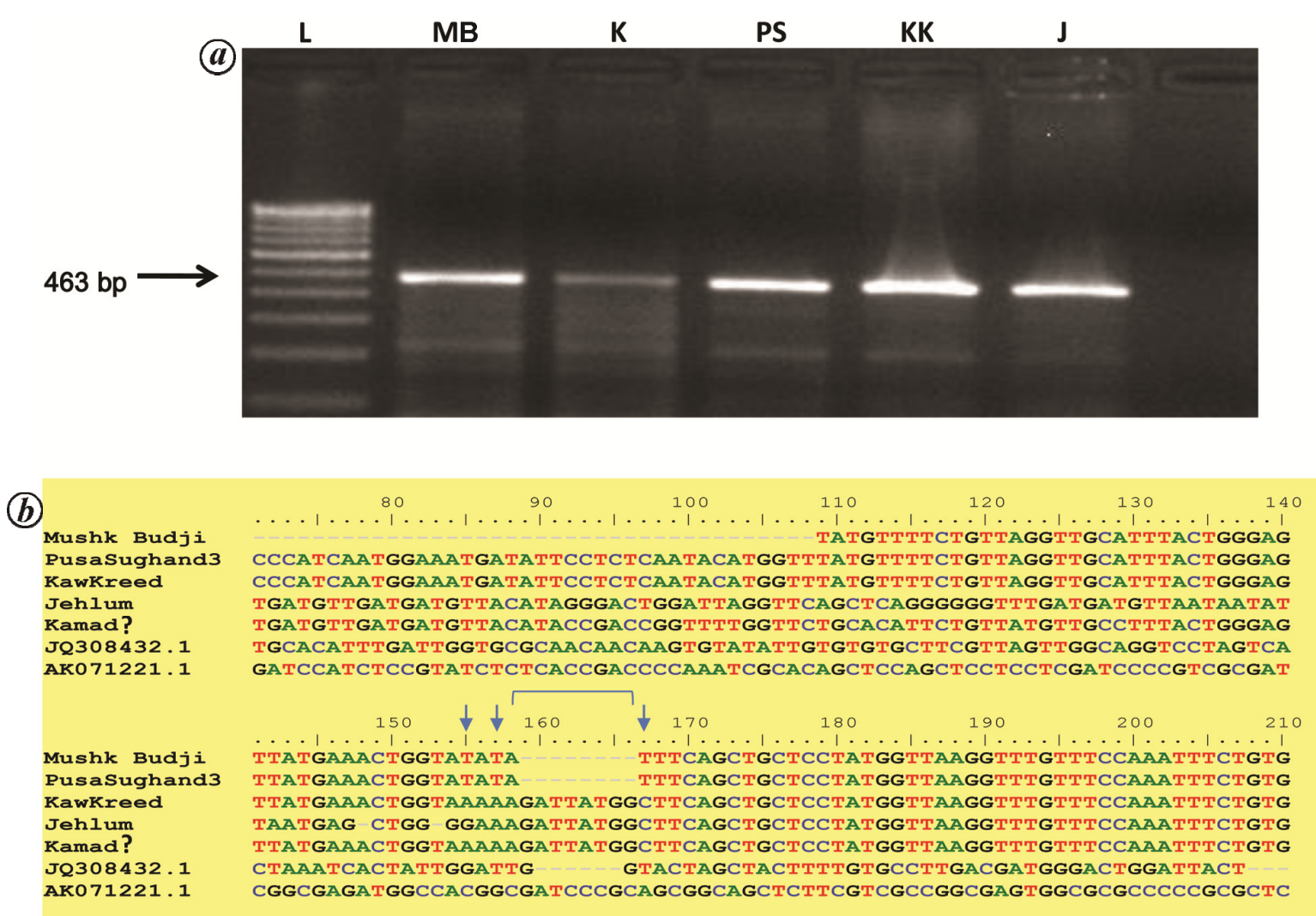

Figure 3. PCR amplification using $O s B A D H 2$ : $\boldsymbol{a}$, Lane L, 100 bp ladder; lane MB, Mushk Budji F; lane K, Kamad?; lane PS, Pusa Sughandh-3, lane KK, Kawa Kreed and lane J, Jehlum. Approximately 463 bp amplicons of exon 7 of rice genotypes were generated for sequencing. $\boldsymbol{b}$, Multiple sequence alignment of selected rice genotypes for exon 7 of badh 2 gene ( 8 bp mutation and 3 SNPS are highlighted by arrows.

also selected due to its disputed nature. OsBADH2 primer pair resulted in the amplification of a $463 \mathrm{bp}$ region covering the target deletion in exon 7 (Figure $3 a$ ). PCRamplified products were sequenced and later analysed using on-line software programmes. BLAST, an algorithm for comparing primary biological sequence information was used to find regions of similarity between the five query sequences and the NCBI database of the biological sequences. Nucleotide BLAST analysis was carried out using algorithms BLASTN (version 2.5.0) and MEGABLAST ${ }^{21,22}$. After annotation the sequences were submitted to NCBI. The accession numbers for the sequences are KT971372.1 (Jehlum), KT971371.1 (Kaw Kreed), KT971370.1 (Pusa Sugandh-3) and KT971369.1 (Mushk Budji).

Multiple sequence alignment using ClustalW clearly shows differences in the region of interest for the five varieties studied (Figure $3 \mathrm{~b}$ ). The expected 8-bp deletion GATTATGG and three SNPs, viz. T and T in place of $A$ and $\mathrm{A}$ before 8-bp deletion and $\mathrm{T}$ in place of $\mathrm{C}$ following 8-bp deletion in exon 7 of aromatic rice genotypes Mushk Budji (Oryza sativa japonica) and Pusa Sugandh-3 (Oryza sativa indica) can be clearly seen in multiple sequence alignment, while the non-aromatic varieties Jehlum (Oryza sativa indica), Kawa Kreed (Oryza sativa japonica) and Kamad? revealed no such deletion. This deletion has been reported earlier in diverse aromatic varieties, namely YRF203, 00210-0-15, YRF207/1202, Yasmin, Amber, Dumsorhk, Dellmont, YRF207, YRF204, 00210-33, Basmati370, Dragon Eyeball 100, Goolarah and Khao Dawk Mali 105, Suyunuo, Wuxiangjing, Pangxiegu, Guanglingxiangnuo, Xiangxuenuo, XiangjingT37, Xiangjing20-18, Wuxiang075, Basmati385, Basmati370, Ganxiangnuo, Meiguomolixiang and Lanka Samurdi ${ }^{12,13,20}$. For Kamad? it was confirmed at both phenotypic and genotypic levels that the accession was not Kamad, and the concerned farmer was growing a contaminated mixture of aromatic and non-aromatic genotypes in his field.

Furthermore, these results suggest that Mushk Budji and Pusa Sugandh-3 may share a common origin. Mushk Budji is considered a landrace of Kashmir and has been relished by the local people since ages. Pusa Sugandh 3 is a released Basmati variety from the Sugandh series obtained by crossing Pusa 1238-1 with Pusa 1238-81-6 (ref. 23). Kovach et al. $^{3}$ have shown that the $5.3 \mathrm{Mb}$ region flanking badh2 in Basmati cultivars is nearly identical to the ancestral japonica haplotype, indicating that Basmati cultivars had close evolutionary relationship with the japonica varietal group.

There are still some unresolved and ambiguous issues regarding the genetic basis of fragrance, and there is little information about the biochemical pathway of rice 


\section{RESEARCH COMMUNICATIONS}

aroma. While Bradbury et $a .^{24}$ suggest that loss of function mutation ( $8 \mathrm{bp}$ deletion in exon 7) leads to production of truncated protein which is incapable of metabolizing aroma compound $2 \mathrm{AP}$ in rice, Chen et al. ${ }^{16}$ have observed that no such truncated protein is formed. According to them ${ }^{16}$, this $8 \mathrm{bp}$ deletion suppresses both transcription and translation of badh2 gene, resulting in 4-aminobutyraldehyde (ABald) accumulation, which otherwise is metabolized by functional BADH2 enzyme. Whatever may be the case, either truncation of protein or inhibited transcription and translation, deletion in exon of badh2 gene imparts rice its characteristic aroma. This is further proven when downregulation of badh2 levels by RNA interference causes enhanced aroma production through accumulation of 2AP (ref. 25).

This study presents unequivocal evidence both at phenotypic and genotypic levels, for fragrance in Mushk Budji and Pusa Sugandh 3. The outcome could provide a stepping stone for effective rice development programmes for Kashmir, especially for introgression of aroma in cold-tolerant genotypes in the temperate and high-altitude regions of Kashmir valley. Marker-assisted selection will decrease the cost of variety development as well as significantly accelerate the introgression of the fragrance gene into these rice varieties.

Conflict of interest: The authors declare no conflict of interest.

1. Sakthivel, K., Sundaram, R. M., Shobha-Rani, N., Balachandran, S. M. and Neeraja, C. N., Genetic and molecular basis of fragrance in rice. Biotechnol. Adv., 2009, 27, 468-473.

2. Buttery, R. G., Ling, L. C. and Juliano, B. O., 2-Acetyl-1pyrroline; an important aroma component of cooked rice. Chem. Ind. (London), 1982, 23, 958-959.

3. Kovach, M. J., Calingacion, M. N., Fitzgerald, M. A. and McCouch, S. R., The origin and evolution of fragrance in rice (Oryza sativa L.). Proc. Natl. Acad. Sci. USA, 2009, 106, 14444 14449 .

4. Parray, G. A., Shikari, A. B., Ganai, M. A. and Husaini, A. M., Local aromatic rice cultivars of North Himalayas - present status and future strategies for their sustainable improvement. Crop Resour., 2008 36, 380-381.

5. Husaini, A. M., Parray, G. A., Rather, A. G. and Sanghera, G. S., Performance of elite basmati rice varieties of subtropical India under valley temperate conditions of Kashmir. Int. Rice Res. Notes, 2009, 1-5.

6. Husaini, A. M., Parray, G. A. and Wani, S. A., Biodiversity of rice germplasm and its conservation in Kashmir: targets, accomplishments and way forward. In University Research in Kashmir RiceA Historical Perspective, SKUAST-K University Publn, 2013.

7. Yano, M., Shimosaka, E., Sato, A. and Nakagahra, M., Linkage analysis of a gene for scent in indica rice variety, Surjamkhi, using restriction fragment length polymorphism markers (in Japanese). Jpn. J. Breed., 1991, 41, 338-339.

8. Hien, N. L., Yoshihashi, T., Sarhadi, W. A. and Hirata, Y., Sensory test for aroma and quantitative analysis of 2-acetyl-1-pyrroline in Asian aromatic varieties. Plant Prod. Sci., 2006, 9, 294-297.

9. Ahn, S. N., Bollich, C. N. and Tanksley, S. D., RFLP tagging of a gene for aroma in rice. Theor. Appl. Genet., 1992, 84, 85-828.
10. Ren, J. S., Xiao, P. C., Chen, Y., Huang, X. and Wu, X. J., Study on heredity of aroma genes in several maintainer lines of aromatic rice. Seed, 2004, 25, 778-781.

11. Wanchana, S., Kamolsukyunyong, W., Ruengphayak, S., Toojinda, T. and Tragoonrung, S., A rapid construction of a physical contig across a $4.5 \mathrm{~cm}$ region for rice grain aroma facilitates marker enrichment for positional cloning. Sci. Asia, 2005, 31, 299-306.

12. Bradbury, L. M., Fitzgerald, T. L., Henry, R. J., Jin, Q. and Waters, D. L., The gene for fragrance in rice. Plant Biotechnol., 2005, 3, 363-370.

13. Shi, W., Yang, Y. I., Chen, S. and Xu, M. Discovery of a new fragrance allele and the development of functional markers for the breeding of fragrant rice varieties. Mol. Breed., 2008, 22, 185192.

14. Sun, S. X., Gao, F. Y., Lu, X. J. and Wu, X. D., Genetic analysis and gene fine mapping of aroma in rice (Oryza sativa L. Cyperales, Poaceae). Genet. Mol. Biol., 2008, 31, 532-538.

15. Bourgis, F., Guyot, R., Gherbi, H., Tailliez, E. and Amabile, I., Characterization of the major fragrance gene from an aromatic japonica rice and analysis of its diversity in Asian cultivated rice. Theor. Appl. Genet., 2008, 117, 353-368.

16. Chen, S., Yang, Y., Shi, W., Jin, Q. and He, F., BADH2, encoding betaine aldehyde dehydrogenase, inhibits the biosynthesis of 2 acetyl-1-pyrroline, a major component in rice fragrance. Plant Cell, 2008, 20, 1850-1861.

17. Sakthivel, K., Shobha-Rani, N., Pandey, M. K., Sivaranjani, A. K. P. and Neeraja, C. N., Development of a simple functional marker for fragrance in rice and its validation in Indian Basmati and nonBasmati fragrant rice varieties. Mol. Breed., 2009, 24, 185-190.

18. Berner, D. K. and Hoff, B. J., Inheritance of scent in American long grain rice. Crop Sci., 1986, 26, 876-878.

19. Saghai-Maroof, M. A., Biyashev, R. M., Yang, G. P., Zhang, Q. and Allard, R., Extraordinarily polymorphic microstatallite DNA in barley genome mapping: species diversity, chromosomal location and population dynamics. Proc. Natl. Acad. Sci. USA, 1994, 91, 5466-5470.

20. Wettewa, W. and Kottearahchi, N. S., Sequence analysis of the mutation in the 7 th exon of $B A D H 2$ gene in traditional aromatic rice varieties in Sri Lanka. J. Agric. Sci., 2014, 9, 1.

21. Zhang, Z., Schwartz, S., Wagner, L. and Miller, W., A greedy algorithm for aligning DNA sequences. J. Comput. Biol., 2000, 7, 203-214.

22. Morgulis, A., Coulouris, G., Raytselis, Y., Madden, T. L., Agarwala, R. and Schäffer, A. A., Database indexing for production MegaBLAST searches. Bioinformatics, 2008, 24, 1757-1764.

23. Siddiq, E. A., Vemireddy, L. R. and Nagaraju, J., Basmati rices: genetics, breeding and trade. Agric. Resour., 2012, 1, 25-36.

24. Bradbury, L. M. T., Gillies, S. A., Brushett, D. J., Waters, D. L. E. and Henry, R. J., Inactivation of an aminoaldehyde dehydrogenase is responsible for fragrance in rice. Plant Mol. Biol., 2008, 68, 439-449.

25. Niu, X., Tang, W., Huang, W., Ren, G. and Wang, Q., RNAidirected downregulation of $\mathrm{OSBADH} 2$ results in aroma (2-acetyl1-pyrroline) production in rice (Oryza sativa L.). BMC Plant Biol., 2008, 8, 100 .

ACKNOWLEDGEMENTS. We thank Dr G. A. Parray and Prof. F. A. Zaki for their help. This study received in-house funding from the Division of Plant Biotechnology, Sher-e-Kashmir University of Agricultural Sciences and Technology of Kashmir, Shalimar.

Received 26 November 2017; revised accepted 28 February 2019

doi: $10.18520 / \mathrm{cs} / \mathrm{v} 118 / \mathrm{i} 4 / 625-629$ 